\title{
Lipid Production by Black Soldier Fly and Fruit Beetle Larvae Alone or When Grown on Dog Feces-A Potential Source of Biodiesel?
}

\author{
Salah A. Jaber ${ }^{1,2 *}$ \\ ${ }^{1}$ Department of Zoology, Al-bayda-Libya Faculty of Arts and Sciences, Omar Al - Mukhtar \\ University, Derna \\ ${ }^{2}$ Department of Molecular Biology and Biotechnology, University of Sheffield, \\ Sheffield S102TN \\ *Corresponding author
}

\section{A B S T R A C T}

\section{Keywords}

Dog feces, Hermatia illucens, Pachnodia marginata peregrine, Biodiesel, Lipid composition

Article Info

Accepted:

10 February 2018

Available Online:

10 March 2018
The potential for using dog feces and dog feces treated with the larvae of the Black Soldier Fly (Hermatia illucens) and Fruit Beetle (Pachnodia marginata peregrina) as a source of biodiesel was determined. It was shown that potential biodiesel precursors (mainly fatty acids) were present in the larvae themselves and in both raw dog feces and the feces treated with the two different larvae. While the addition of the larvae to dog feces did not increase the amount of fatty acids produced they did alter the lipid composition. It is concluded that these larvae alone could be used as a source of lipids for biodiesel production, especially when grown on wastes as part of a composting process; the use of dog feces for this purpose or foe the large-scale production of individual lipids, whether treated or not with larvae is however, likely to be limited by the economics of bulk collection of this material.

\section{Introduction}

Biodiesel is receiving increased attention as a renewable source of fuel. Biofuels can be made from a variety of feed stocks including starch, vegetable oil, or animal fats as a fuel alternative to help reduce consumption of petroleum (Demirbas, 2009, Gerpen, 2005). Alternatively, cheap waste, such as dairy manure can be used to produce bioethanol (Liao et al., 2008) and is hoped that, as well as producing biofuels, a reduction can be made in the amount of waste which has to be disposed of to the environment (Ann et al., 2002).
Currently, biodiesel is generally used as a diesel fuel additive to minimize particulate release and the production of carbon monoxide, and hydrocarbons (Demirbas, 2009). The relatively high production cost is the main reason why biodiesel is not used as a primary fuel. Three quarters of the cost of biodiesel is derived from the feedstock, such as soybean oil, rapeseed oil and sunflower oil (Gerpen, 2005). In addition, the use of limited food supplies for the production of biodiesel is not feasible for developing countries like China. As a result, non-food feed stocks such as Jatropha curcas, Chinese tallow and 
microalgae are being developed as sources of biofuels; the use of these sources however, is certainly not without problems (Demirbas, 2009). On the other hand, organic wastes such as animal wastes, residential wastes (e.g., household), commercial and institutional wastes are generated in large quantities in developing countries and present a cheap from of organic wastes which would otherwise present an environmental pollution problem and so can act as a useful resource for biodiesel production (Ma and Hanna, 1999).

Biodiesel production by Black Soldier Fly larvae (BSFL) and Fruit Beetle larvae (FBL)

Animal feces can be used for biodiesel production, with the resultant biodiesel being comparable to rapeseed based biodiesel, and met the European biodiesel standard, EN14214. (Gerpen, 2005). Among the organic wastes evaluated, chicken manure appears to be the best one for achieving high rates of Black Soldier Fly biomass production.

About $30 \%$ of the waste-grown BSFL biomass can be extracted as crude fat, which can be used for the production of biodiesel; the resultant fuel properties of the BSFL fat-based biodiesel, including density $(885 \mathrm{~kg} / \mathrm{m} 3)$, viscosity $(5.8 \mathrm{~mm} 2 / \mathrm{s})$, and cetane number (53) were found to be similar to those of rapeseed oil based biodiesel (Li et al., 2011a, b, c). Among the organic wastes evaluated chicken manure was found to be the best for maximal BSFL growth (327.6 g), which gave $8.5 \mathrm{~g}$ crude fat production after petroleum ether extraction. An optimized two step conversion process was performed, yielding $91.4 \mathrm{~g}$ of biodiesel with a biodiesel yield of $93 \%$ from the crude fat contents (Li et al., 2011c). Cattle, pig and chicken manure can also act as a food source for the production of high fat, nutrientrich larvae. Fat-rich BSFL can be used to degrade organic waste and produce biodiesel as well as providing foods from animals notably chickens (Li et al., 2011b).

The results of recent studies have shown that BSFL-produced fatty acids could be a valuable feedstock for biodiesel production having two advantages over crop oil-based biodiesel, namely: 1) It does not compete with food resources or land use 2) It uses waste nutrients for insect growth. The aim of the work reported here was to determine if the larvae used here can convert dog feces into a potentially viable source of biodiesel. To date there appears to be no reports of the use of dog feces to produce biodiesel, either alone or in conjunction with BSFL or FBL. The aim of the work reported here was aimed at determining the lipid composition of the two and dog feces alone and to determine the effect of adding these larvae to dog feces on the amount and types of lipids produced from this common waste product.

\section{Materials and Methods}

Black soldier fly (BSFL, Hermatia illucens)) and Fruit Beetle larvae (Pachnodia marginata peregrina) were obtained from Live Food Co., while dog feces samples were collected from local dog waste bins. The feces were distributed in two boxes, each containing $100 \mathrm{~g}$ of dog feces. Ten BSFL were then added to the waste (1000 larvae per $\mathrm{kg}$ dog waste) according to $\mathrm{Li}$ et al., (2011) and ten FB larvae were similarly added to the dog feces. The treated feces were incubated under laboratory conditions for 28 days; samples were then removed in triplicate at weekly intervals.

\section{Extraction of lipids}

In order to extract lipids from dog feces and larvae, the larva (whole bodies) were ground and then weekly samples (1 g) of all samples were added to Eppendorf tubes $1.5 \mathrm{ml}$ and 
frozen at $-80 \mathrm{oC}$ overnight, then freeze dried (lyophilized) for 24-48 hours. To estimate the weight of biomass the Eppendorf tubes were re-weighed. Samples were transferred to centrifuge tubes $(50 \mathrm{ml}), 20 \mathrm{ml}$ of methanol/ chloroform $(2: 1 \mathrm{v} / \mathrm{v})$ were added; the contents were then sonicated for $1 \mathrm{~min}$ on ice. Samples were centrifuged at $5000 \mathrm{~g}$ for $5 \mathrm{~min}$. and transferred to a centrifuge tubes in order to determine the volume of supernatant. Then 2:1 methanol: chloroform, and chloroform and $1 \%$ $\mathrm{NaCl}(1 \mathrm{~g} \mathrm{NaCl}$ in $100 \mathrm{ml})$ was added to give 2:2:1 methanol: chloroform: $1 \% \mathrm{NaCl}$. (13.33ml methanol: 13.33 chloroform: 6.7 $1 \% \mathrm{NaCl}$ ). Samples were then centrifuged for 2 mins at $5000 \mathrm{~g}$. The centrifuge tubes were labelled and weighed then transferred to a chloroform phase into pre-weighed sample were left in fume cupboard with tops open to evaporate until dry. The centrifuge tubes were then re-weighed and the weight of lipids calculated. (Lu et al., 2008; Chiu et al., 2009)

Detection and measurement the fatty acid using a combined mass spectrometer and gas chromatographic GC/MS

The harvested lipids $(10 \mathrm{mg} / \mathrm{ml})$ of dog feces and BSF and FB larvae before and after being fed on dog feces were dissolved in chloroform. The samples were then subjected to gas chromatography-mass spectrometry GC/MS.

The GC/MS analyses were performed using a Perkin Elmer Turbo mass spectrometer detector (software version 5.4. Perkin Elmer). Injector and oven temperatures were set as above with a transfer line temperature, $260^{\circ} \mathrm{C}$. The injection volume was $1.0 \mu \mathrm{l}$ of dog feces and larvae and was injected in a capillary column (Zebran ZB-S, 30 m length x $0.25 \mathrm{~mm}$ diameter $\mathrm{x} 0.25 \mu \mathrm{m}$ phase thickness) (see appendix 4). The oven temperature was programmed from $60^{\circ} \mathrm{C}$ and increased at the rate of $10^{\circ} \mathrm{C} / \mathrm{min}$ to a final temperature of $260^{\circ} \mathrm{C}$, which was held for $10 \mathrm{~min}$. High purity helium was used as carrier gas at $1 \mathrm{ml} / \mathrm{min}$, split ratio and 1:25; Electron ionization (EI) spectra were obtained at $70 \mathrm{eV}$; the scan range was $50-450 \mathrm{~m} / \mathrm{z}$ at $30 \mathrm{~min}$. The identity of each compound was determined by comparison of its retention index (RI) as well as of its total ion chromatogram with the NIST mass spectral library version 5.4.2 (Albano et al., 2011; Sivasamy et al., 2011).

\section{Results and Discussion}

\section{Extraction of biodiesel from larvae}

A visual representation of the fact that lipids could be extracted from the feces on which larvae were grown and from the larvae themselves is shown in Figure 1, while Table 1 shows the percentage of lipids present in the dog feces, in larvae fed on feces and in the larvae themselves as well as the effect of individually adding the two larvae on lipid production in the feces.

Untreated dog feces (without larvae) possessed a lipid content of $71 \%$ (Table 1). The unfed larvae, BSFL and FBL, contained 85 and $50 \%$ dry weight of lipids. This suggests that both types of dog feces and the two larvae could be used independently as a source of lipids for the production of biofuels. The next step was to determine if feeding the larvae on dog feces would increase, over time, their lipid content and the lipid content of the feces on which they were feeding. The results of the week 1 analysis show (Table 1) that the lipid content of the dog feces treated with BSFL and FBL fell from 71 to 14 and $27 \%$ respectively, while the lipid content of the two larvae remained broadly the same as before feeding on feces. By week 2, the lipid content of the dog feces treated with BSFL and FBL declined, as did the concentration of lipids in both types of larvae (Table 1); this trend was also seen at weeks 3 and 4 (Table 1). 
Fig.1 Fatty acids extracted from; a, BSFL, b) FBL, c) dog feces with BSFL, d) Dog feces with FBL

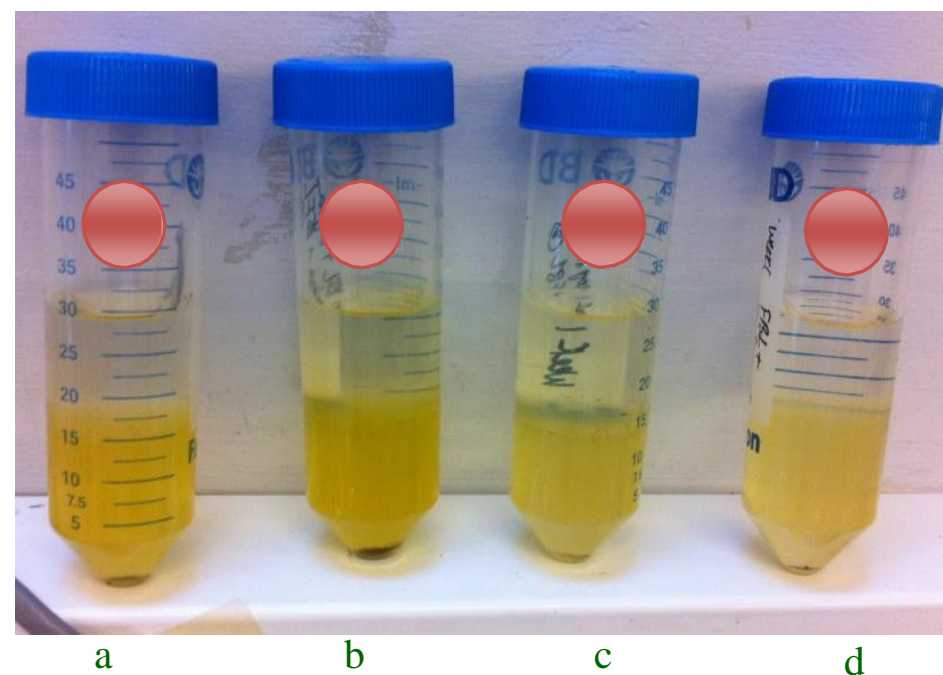

Table. 1 The percentage of lipids in dry weight of $1 \mathrm{~g}$ samples of feces and larvae

\begin{tabular}{|l|l|l|l|}
\hline Time/ week & $\begin{array}{l}\text { Dry weight/g } \\
\text { SD } \pm\end{array}$ & $\begin{array}{l}\text { Total lipids/ } \\
\text { SD } \pm\end{array}$ & $\begin{array}{l}\% \text { of lipids in } \\
\text { dry weight }\end{array}$ \\
\hline Zero time & & & \\
\hline Untreated dog feces (without larvae) & $0.21 \pm 0.01$ & $0.15 \pm 0.02$ & $71 \%$ \\
\hline BSFL before fed on dog feces & $0.26 \pm 0.01$ & $0.22 \pm 0.02$ & $85 \%$ \\
\hline FBL before fed on dog feces & $0.20 \pm 0.01$ & $0.10 \pm 0.02$ & $50 \%$ \\
\hline Week 1 & & & \\
\hline Dog feces with BSFL & $0.70 \pm 0.05$ & $0.10 \pm 0.00$ & $14 \%$ \\
\hline Dog feces with FBL & $0.44 \pm 0.04$ & $0.12 \pm 0.01$ & $27 \%$ \\
\hline BSFL fed on dog feces & $0.28 \pm 0.01$ & $0.23 \pm 0.01$ & $82 \%$ \\
\hline FBL fed on dog feces & $0.25 \pm 0.02$ & $0.14 \pm 0.03$ & $56 \%$ \\
\hline Week 2 & $0.90 \pm 0.02$ & $0.10 \pm 0.02$ & $11 \%$ \\
\hline Dog feces with BSFL & $0.80 \pm 0.02$ & $0.14 \pm 0.01$ & $18 \%$ \\
\hline Dog feces with FBL & $0.50 \pm 0.02$ & $0.15 \pm 0.02$ & $30 \%$ \\
\hline BSFL fed on dog feces & $0.60 \pm 0.01$ & $0.14 \pm 0.04$ & $23 \%$ \\
\hline FBL fed on dog feces & & & \\
\hline Week 3 & $0.90 \pm 0.03$ & $0.23 \pm 0.03$ & $26 \%$ \\
\hline Dog feces with BSFL & $0.80 \pm 0.02$ & $0.22 \pm 0.02$ & $28 \%$ \\
\hline Dog feces with FBL & $0.50 \pm 0.02$ & $0.16 \pm 0.04$ & $32 \%$ \\
\hline BSFL fed on dog feces & $0.70 \pm 0.02$ & $0.13 \pm 0.01$ & $19 \%$ \\
\hline FBL fed on dog feces & & & \\
\hline Week 4 & $0.80 \pm 0.01$ & $0.23 \pm 0.01$ & $29 \%$ \\
\hline Dog feces with BSFL & $0.84 \pm 0.02$ & $0.20 \pm 0.02$ & $24 \%$ \\
\hline Dog feces with FBL & $0.62 \pm 0.04$ & $0.16 \pm 0.02$ & $26 \%$ \\
\hline BSFL fed on dog feces & $0.82 \pm 0.02$ & $0.14 \pm 0.01$ & $17 \%$ \\
\hline FBL fed on dog feces & & & \\
\hline
\end{tabular}


Table.2 The GC/MS analysis chain composition of a number of fatty acids from dog feces and larval fats

\begin{tabular}{|c|c|c|c|c|c|c|c|c|c|c|c|c|c|c|c|c|c|c|c|}
\hline & 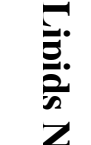 & & $\begin{array}{c}\text { Time } \\
\text { Week } 0\end{array}$ & & Week & & & & Weel & & & & Wee & & & & Week & & \\
\hline Fatty acid & $\stackrel{\bar{E}}{\overline{\underline{T}}}$ & 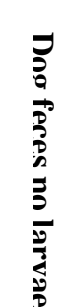 & 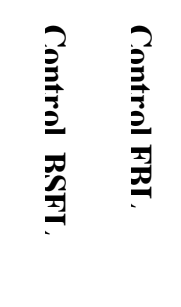 & 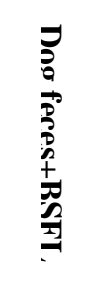 & 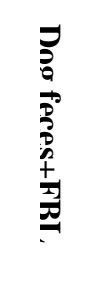 & 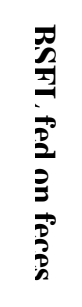 & 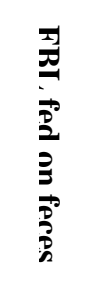 & 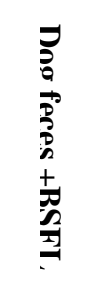 & 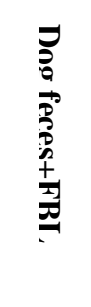 & 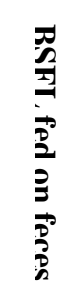 & 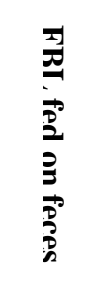 & 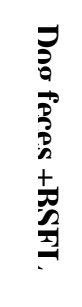 & 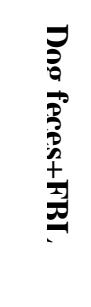 & 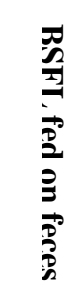 & 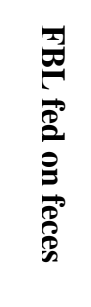 & 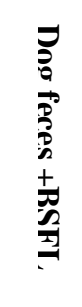 & 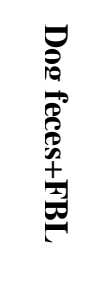 & 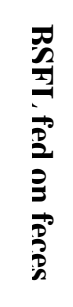 & \\
\hline
\end{tabular}

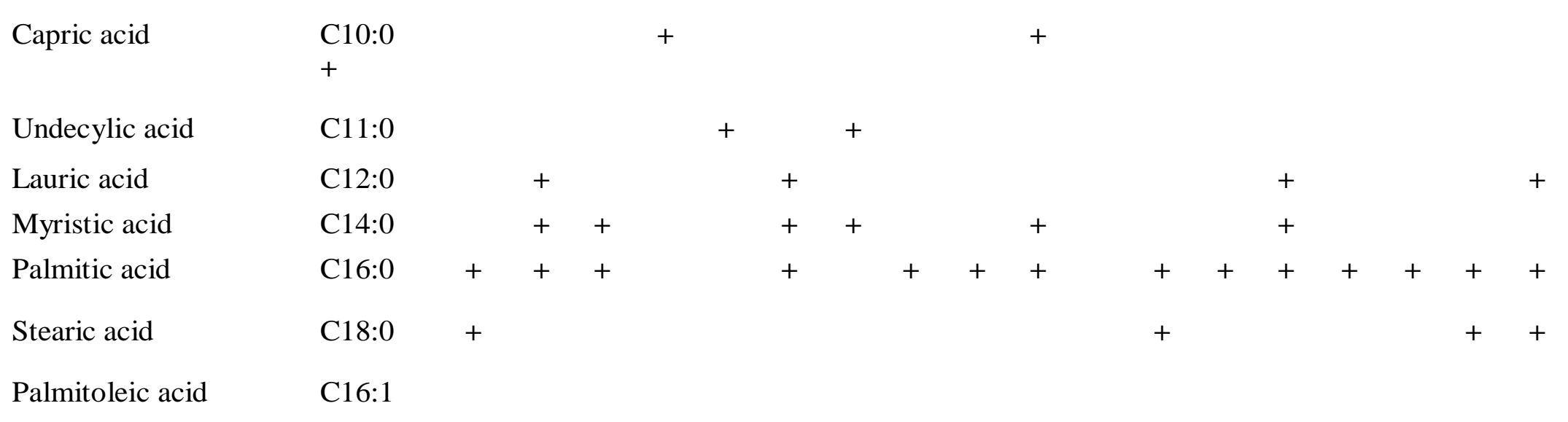

Oleic acid $\mathrm{C} 18: 1+$ 
These results show that the decline in dog feces lipid content was not mirrored by an increase in the lipid content of the two larvae. Presumably, the feces-lipids were, over time, metabolized by the larvae, ultimately to carbon dioxide, i.e. the larvae were using the fecal lipids as a food source. The results show that no advantage can be gained in relation to total lipid production by treating dog feces with BSFL and FBL. However, Table 2 shows that the type and concentration of fatty acids (as seen by referring to peak retention times and peak height respectively of the exhibited chromatograms) varied markedly depended on time of exposure of the larvae to dog feces and the type of larvae used. Dog feces without larvae and unfed FBL contained only palmitic and stearic acids, while unfed BSFL contained these fatty acids together with lauric acid.

The type of fatty acid produced in the larvae and in the dog feces on which the larvae fed was then seen to vary over time. Oleic acid, for example was only produced in the BSFL fed on dog feces and then only at week 2 (Table 2). Clearly, the type of fatty acid varied with the larvae used and in the feces treated with the different larvae, all of which varied over time. This finding suggests that BSFL and FBL might be used to produce individual fatty acids, either within their bodies, when fed on dog feces, or in the dog feces itself. In this way a single, or desired mixture of fatty acids, might be produced. Thus, if oleic acid alone was needed as a biofuel feedstock, or for some other biotechnological purpose then feeding BSF on dog feces for 2 weeks and the harvesting the larvae and extracting the fatty acid may provide a source of this individual fatty acid.

The use of BSFL to treat domestic waste has been pioneered by the New York- based Ecosystem Corporation which is asking the US Department of Energy for $\$ 1.75$ million to prove the concept. This Company is also seeking a matching grant from the Dog's Biomass Research and Development Initiative to build a $\$ 3.5$ million demonstration project that would use 24,000 tons of food waste from an Ohio waste transfer station to feed a "bioreactor" full of flies (Otis et al., 1980).

The pilot plant could produce between 150,000 to 195,000 gallons of oil per year; some 26 million tons of food scraps are dumped by Americans into landfills each year, and only about 3 percent of that is being recovered today.

Ecosystem claim that with only one-quarter of all those food scraps it could make 100 million gallons of oil every year; add in livestock manure and other agriculture wastes and that amount could increase - particularly if the company can be paid to take it off waste handlers' hands, a possibility which forms an important part of many waste-to-biofuel business plans (Vaughn, 2009)

Whether raw dog feces, or when treated with larvae like the ones used here, could be used economically as a source of biodiesel remains to be seen. Although vast amounts of dog feces are produced annually all over the world problems relating to such collection are obvious.

The increasing social trend towards dog owners collecting dog feces and placing them in council collection containers means that an increasing amount of this potential bio resource is being collected together, at least in the urban environment. The quantities collected will never however, approach that of other animal feces, such as cattle feedlot waste. As a result, it might be better to use the relatively small amounts of dog feces, which are collected in any one location, for localized methane generation, rather than biodiesel production. 


\section{References}

Albano, S. M., Lima, A. S., Miguel, M. G., Pedro, L. G., Barroso, J. G. and Figueiredo, A. C. 2011. Antioxidant, Anti-5-lipoxygenase and antiacetylcholinesteras activities of essential oils and decoction waters of some aromatic plants. Record Nat. Prod., 6: 35-48.

Ann, C., Walter, W. and Mulbry, W. 2002. Recovery of dairy manure nutrients by benthic freshwater algae. Bioresour Technol., 84: 81-91.

Chiu, S. Y., Kao, C. Y., Tsai, M. T., Ong, S. C., Chen, C. H. and Lin, C. S. 2009. Lipid accumulation and $\mathrm{CO}_{2}$ utilization of Nannochloropsis oculata in response to $\mathrm{CO}_{2}$ aeration. Bioresour Technol., 100: 833-838.

Demirbas, A., 2009. Biofuels: securing the planets future energy needs. Energy Convers. Manag., 50: 2239-2249.

Gerpen, J.V., 2005. Biodiesel processing and production. Fuel Process. Technol., 86: 1097-11107.

Li, Q., Zheng, L., Cai, H., Garza, E., Yu, Z. and Zhou, S. 2011a. From organic waste to biodiesel: Black soldier fly, Hermetia illucens, makes it feasible. Fuel., 90:1545-1548.
Li, Q., Zheng, L., Hou, Y., Yang, S. and Yu, Z. 2011b. Insect fat, a promising resource for biodiesel. J. Pet. Environ. Biotechnol., 2: 2-6.

Li, Q., Zheng, L., Qiu, N., Cai, H., Tomberlin, J. K. and Yu, Z. 2011c. Bioconversion of dairy manure by black soldier fly (Diptera: Stratiomyidae) for biodiesel and sugar production. Waste Manage, 31: 13161320.

Ma, F. and Hanna, M. A. 1999. Biodiesel production: a review. Bioresour Technol., 70: 1-15.

Otis, R. J., Boyle, W. C., Clements, E. V. and Schmidt, C. J. 1980. Design Manual; Onsite Wastewater Treatment and Disposal Systems. Environmental Protection Agency Report EPA-625/180-012, p p. 412.

Sivasamy, R., Angayarkanni, J. and Palaniswamy, M. 2011. A novel filarial topoisomerase II inhibitor produced by native isolate Micrococcus luteus B1252. Afr. J. Biotechnol., 10: 1606916077.

Vaughn, J. 2009. Waste Management: A Reference Handbook. Oxford, ABCCLIO. Pp. 311.

\section{How to cite this article:}

Salah A. Jaber. 2018. Lipid Production by Black Soldier Fly and Fruit Beetle Larvae Alone or When Grown on Dog Feces-A Potential Source of Biodiesel? Int.J.Curr.Microbiol.App.Sci. 7(03): 1083-1089. doi: https://doi.org/10.20546/ijcmas.2018.703.129 